\title{
ANÁLISE ESPACIAL DOS DETERMINANTES SOCIOAMBIENTAIS PARA LEPTOSPIROSE NO MUNICÍPIO DE ITABORAÍ-RJ, ATRAVÉS DA ABORDAGEM ECOSSISTÊMICA
}

\author{
SPATIAL ANALYSIS OF THE SOCIO-ENVIRONMENTAL DETERMINANTS OF \\ LEPTOSPIROSE IN ITABORAÍ MUNICIPALITY - RJ, THROUGH THE ECOSYSTEM \\ APPROACH
}

\author{
Jefferson Pereira Caldas \\ Dr. Epidemiologia (ENSP/FIOCRUZ), LabMep-ENSP-FIOCRUZ \\ jeffeuerj@yahoo.com.br \\ Hermano Albuquerque \\ Dr. Medicina Tropical (IOC/FIOCRUZ), LabMep-ENSP-FIOCRUZ \\ hermanofio@gmail.com \\ Heitor Levy Ferreira Praça \\ Dr. Planejamento Urbano e Regional (IPPUR/UFRJ), LabMep-ENSP-FIOCRU̧Z \\ heitorlevy2@gmail.com
}

Alexandre San Pedro Siqueira Dr. Saúde Pública (ENSP/FIOCRUZ), CEPIDSS-ENSP-FIOCRUZ alexsan.rj@gmail.com

Luciano Medeiro de Toledo Dr. Saúde Pública (ENSP/FIOCRUZ), LabMep-ENSP-FIOCRUZ luciano.toledo@ensp.fiocruz.br

Paulo Chagastelles Sabroza

Msc. Saúde Pública (ENSP/FIOCRUZ), LabMep-ENSP-FIOCRUZ psabroza@gmail.com

\begin{abstract}
RESUMO
As abordagens ecossistêmicas surgem como enfoques alternativos que integram múltiplos aspectos para a compreensão e busca de soluções de problemas de saúde oriundos de precárias condições sociossanitárias. A vulnerabilidade para a leptospirose é marcada por áreas onde há propensão a ocorrer desastres naturais de alagamento associados a precárias condições sociossanitárias. O presente artigo traz a identificação de áreas de risco para leptospirose no município de Itaboraí considerando características ambientais e sociossanitárias relacionadas a produção da doença. A análise espacial foi realizada por meio de sobreposição dos temas de interesse: áreas de maior risco de inundação (28\% do território), áreas críticas $(0,9 \%$ do território e $9,3 \%$ da população do município) e casos notificados de leptospirose, através da análise visual. Dos 89 casos de leptospirose notificados, $71 \%$ foram localizados dentro das áreas de influência de inundação e $34 \%$ em localidades com precárias condições sociossanitárias. Os resultados alcançados com a integração das informações socioambientais do território e análise da distribuição espacial da leptospirose demonstra a ocorrência injusta, desproporcional e evitável de leptospirose naquelas localidades, ressaltando uma situação de iniquidade social em saúde na qual populações com menores condições econômicas são impelidas a ocupar porções do território ambientalmente degradadas e com menor disponibilidade de serviços. Essa se mostra uma promissora abordagem para a área da vigilância.
\end{abstract}

Palavras-chave: Vulnerabilidade. Inundação. Áreas Críticas. Leptospirose. Modelagem Espacial.

Recebido em: 13/10/2019

Aceito para publicação em: 11/11/2019

Artigo apresentado IX Simpósio Nacional de Geografia da Saúde, Blumenau, SC, 2019. 
Análise espacial dos determinantes socioambientais para leptospirose no município de Itaboraí-RJ, através da abordagem ecossistêmica
Jefferson Pereira Caldas

Hermano Albuquerque Heitor Levy Ferreira Praça

Alexandre San Pedro Siqueira

Luciano Medeiro de Toledo

Paulo Chagastelles Sabroza

\begin{abstract}
Ecosystem approaches emerge as alternative to integrate multiple aspects of health problems arising from precarious socio-sanitary conditions to understand and search for solutions. The vulnerability to leptospirosis is associated to areas where there is a tendency to occur natural flooding disasters associated with precarious socio-sanitary conditions. This manuscript present the identification of leptospirosis risk areas in the Itaboraí municipality, considering environmental and socio - sanitary characteristics related to the disease production. The spatial analysis was performed by overlapping the themes of interest: flood risk areas (28\% of the territory), critical areas $(0.9 \%$ of the territory and $9.3 \%$ of the population of the municipality) and reported cases of leptospirosis through visual analysis. Of the 89 reported cases of leptospirosis, $71 \%$ were located within the flood areas and $34 \%$ in locations with poor socio-sanitary conditions. The integration of socioenvironmental data and analysis of the leptospirose spatial distribution demonstrate the unfair, disproportionate and avoidable occurrence of the disease in those localities, highlighting a situation of social inequity in health in which populations with lower economic conditions are impelled to occupy portions of the territory environmentally degraded and with less availability of services. This shows a promising surveillance approach.
\end{abstract}

Keywords: Vulnerability. Flooded Areas. Critical Areas. Leptospirosis. Spatial Modeling.

\title{
INTRODUÇÃO
}

Nos últimos 50 anos, a sociedade humana vem impactando os ecossistemas mais rápida e extensivamente do que em qualquer outro período da história. Aproximadamente $60 \%$ dos serviços dos ecossistemas estão sendo degradados ou utilizados de modo insustentável, com custos ambientais, humanos e econômicos difíceis de estimar. A exploração não sustentável destes sistemas em grande parte objetiva atender à crescente demanda de consumo e a maximização dos lucros. Existem evidências que a exploração insustentável desses sistemas aumenta as chances de mudanças não-lineares abruptas e irreversíveis nos ecossistemas, ocasionando importantes consequências para as condições de vida e saúde das populações humanas e do ambiente. Os efeitos negativos da degradação dos serviços dos ecossistemas ocorrem de modo desproporcional entre os segmentos socioeconômicos, raciais e de gênero das populações, sendo as mulheres, as negras e os mais pobres os mais impactados. Contribuindo assim para crescentes iniquidades e disparidades, constituindo-se também em fator na origem e perpetuação da pobreza e de conflitos sociais (MEA, 2005).

Por sua própria natureza complexa, estes problemas requerem a busca de enfoques alternativos que integrem os aspectos socioeconômicos com os biofísicos na compreensão e busca de soluções dos mesmos. As abordagens ecossistêmicas têm surgido como uma destas alternativas em termos de abordagens integradas que permitam cientificamente compreender as mudanças nos ecossistemas de modo holístico e não setorial, orientado para a tomada de decisão (Rosen et al., 2000).

A leptospirose tem como agente etiológico uma bactéria aeróbica do gênero Leptospira com mais de 200 sorotipos já identificados, estes estão relacionados com as diversas manifestações clínicas no homem. O quadro clínico pode variar desde infecções assintomáticas até formas graves, inclusive levando óbito. Apresenta alta letalidade, podendo chegar a $40 \%$ dos casos (Brasil, 2017). A Leptospira tem a valência de viver em diferentes habitats se mantendo infeciosa no ambiente por períodos prolongados. A infecção acontece por meio do contato direto da bactéria com mucosas ou ferimentos, através de água, solo ou alimentos contaminados pela urina de animais reservatórios infectados (Gonçalves-de-Albuquerque, 2012). Os principais reservatórios são os roedores popularmente conhecidos como: ratazanas, rato preto $e$ camundongo (Rattus norvegicus, Rattus rattus e Mus musculus), que por sua vez não manifestam a doença, apesar de alojarem o agente infecioso nos rins liberando as leptospira pela 
Análise espacial dos determinantes socioambientais para leptospirose no município de Itaboraí-RJ, através da abordagem ecossistêmica
Jefferson Pereira Caldas Hermano Albuquerque Heitor Levy Ferreira Praça Alexandre San Pedro Siqueira Luciano Medeiro de Toledo Paulo Chagastelles Sabroza

urina contaminando assim água, solos e alimentos. As ratazanas são os principais reservatórios do sorotipo Icterohaemorraghiae, um dos mais patogênicos para o homem (Brasil, 2017).

A leptospirose inicialmente ocorria esporadicamente em áreas rurais. Contudo, com o advento da urbanização desordenada ela ocupou também as áreas urbanas. No mosaico heterogêneo das cidades, a leptospirose ocorre principalmente nos nichos onde existe precariedade de serviços de saneamento, que propiciam uma maior proliferação dos vetores e em áreas propícias a inundação, que possibilitam em épocas de chuvas uma maior dispersão do patógeno pelo ambiente (Aleixo; Sant'anna Neto, 2010). Além disto, estas áreas são geralmente destinadas as populações marginalizadas no processo de ocupação do tecido urbano. Dessa forma, ela se torna uma doença preocupante para saúde pública pela gravidade e o modo de disseminação em áreas urbanas, podendo causar surtos epidêmicos nos períodos de chuvas, sobretudo nos grandes conglomerados humanos de baixa renda (Gonçalves-de-Albuquerque, 2012).

O crescimento da população global, a pobreza, a escassez de terra e a urbanização têm aumentado o número de pessoas que vivem em áreas propensas a desastres. Nos últimos anos, as inundações aumentaram em frequência e intensidade nos centros urbanos, seja em função das condições naturais ou das atividades humanas, como o desmatamento, a degradação do solo, a urbanização e a drenagem ineficiente. As enchentes e inundações correspondem a quase $80 \%$ dos eventos ambientais adversos registrados no país. Entre 2003 a 2007, foram notificados pela Defesa Civil 1.865 desastres. Destes, 1.483 (79,5\%) estavam associados às inundações (Cerutti, 2007). O crescimento da população em áreas urbanas, a degradação ambiental e o precário saneamento ambiental, assim como a falta de infraestrutura urbana, resultantes da ausência de planejamento urbano e ambiental, e também as mudanças climáticas, são fatores que agravam as consequências sociais e ambientais destes eventos (Solomon et al., 2007).

As inundações são um processo natural que sofre influência direta e indireta das ações antrópicas e são produto de um processo dialético entre os seres humanos e os sistemas ambientais, interagindo num processo contínuo. No que diz respeito aos impactos humanos, as inundações combinam condições ambientais e sociais. Nesse processo, os grupos populacionais e os espaços geográficos mais vulneráveis são os mais fortemente afetados (Freitas \& Ximenes, 2012).

Nesse contexto torna-se muito importante a identificação e delimitação das áreas de maior risco para eventos deste tipo, de forma que o poder público possa intervir nas mesmas e, através de ações que minimizem os impactos causados pela ação antrópicas, reduzir os efeitos das enchentes na dinâmica social.

No Brasil, durante um século marcado por intenso processo de urbanização, os assentamentos precários, como soluções habitacionais produzidas mediante processos que combinam em diferentes escalas a iniciativa autônoma da população de baixa renda e a interferência do mercado designado como informal ou clandestino, se tornaram a forma predominante de moradia popular, refletindo a histórica desigualdade de distribuição da terra e da riqueza produzida no país (Brasil, 2009).

A análise social do território deve contribuir para construir identidades; revelar subjetividades; coletar informações; identificar problemas, necessidades e positividades dos lugares; tomar decisão e definir estratégias de ação nas múltiplas dimensões do processo de saúde-doençacuidado. Os diagnósticos de condições de vida e situação de saúde devem relacionar-se tecnicamente ao trinômio estratégico 'informação-decisão-ação' (Teixeira et al., 1998).

Segundo Heidegger, 1998:

Localizar significa mostrar o lugar. Quer dizer, além disto, reparar no lugar. Ambas as coisas, mostrar o lugar e reparar no lugar, são os passos preparatórios de uma localização. Mas é muita ousadia que nos conformemos com os passos preparatórios. A localização termina, como corresponde a todo método intelectual, na interrogação que pergunta pela situação do lugar . 
Análise espacial dos determinantes socioambientais para leptospirose no município de Itaboraí-RJ, através da abordagem ecossistêmica
Jefferson Pereira Caldas Hermano Albuquerque Heitor Levy Ferreira Praça Alexandre San Pedro Siqueira Luciano Medeiro de Toledo Paulo Chagastelles Sabroza

A delimitação de áreas críticas sociossanitárias através da análise social do território é um método e expressão geográfica, que permite a gestores, instituições, profissionais e usuários do SUS compreender a dinâmica espacial dos lugares e de populações; os múltiplos fluxos que animam os territórios; e as diversas paisagens que emolduram o espaço da vida cotidiana.

Considerando que é na interface entre os aspectos socioeconômicos e os biofísicos que são conformadas as situações socioambientais que resultam nas mudanças nos ecossistemas e seus serviços, bem como o quadro de saúde das populações humanas, este trabalho tem por objetivo delimitar as áreas de maior risco de inundação através de modelagem espacial, delimitar as áreas de maior criticidade sociossanitária através do reconhecimento territorial a nível local e analisar a vulnerabilidade socioambiental do município de Itaboraí para Leptospirose através da sobreposição das áreas de inundação e áreas críticas com os casos notificados de Leptospirose georreferenciados.

Itaboraí é uma cidade que sofre de forma recorrente os eventos de inundação desde a era colonial até os dias de hoje apesar das intervenções de engenharia realizadas nas bacias hidrográficas do município (INEA, 2014; Itaboraí, 2018). Além disto apresenta endemicidade para Leptospirose em surtos epidêmicos nos anos que ocorrem eventos de inundação.

Itaboraí passou e ainda passa por um processo de grande transformação de seu espaço urbano por conta da implantação do Complexo Petroquímico do Estado do Rio de Janeiro (COMPERJ) que se iniciou no ano de 2008. Inicialmente a cidade experimentou um grande crescimento econômico e na sua dinâmica urbana advindo dos investimentos na construção civil e dos empregos gerados na obra do complexo. Contudo com a crise ocorrida na PETROBRAS em 2015 e a consequente paralização das obras, a cidade entrou num processo de grande decadência econômica. Nos dias atuais as obras foram retomadas parcialmente gerando algum tipo de dinâmica na economia do município, mas ainda longe do que se apresentou até a crise.

Este trabalho foi realizado dentro do contexto do Plano de Monitoramento Epidemiológico da Área de Influência do COMPERJ realizado pelo Laboratório de Monitoramento Epidemiológico de Grandes Empreendimentos (LabMep) da Escola Nacional de Saúde Pública (ENSP) da Fundação Oswaldo Cruz (Fiocruz) que objetivava o monitoramento analítico da evolução de doenças e agravos na área de influência do COMPERJ visando contribuir para minimizar os riscos de adoecimento e morte que eventualmente poderiam emergir em decorrência da implementação do empreendimento.

O estudo espera contribuir no debate acerca dos determinantes socioambientais para Leptospirose, visando servir ao poder público como um importante instrumento de auxílio a tomada de decisão que possibilite ações mais direcionadas as áreas mais vulneráveis otimizando assim recursos e maximizando resultados.

\section{METODOLOGIA}

\section{Área de Estudo}

Itaboraí pertence à Região Metropolitana do Rio de Janeiro com uma área total de 429,3 quilômetros quadrados. Os limites municipais são: Guapimirim e Cachoeiras de Macacu ao Norte, Tanguá a Leste, Maricá ao Sul, São Gonçalo e Baía de Guanabara a Oeste. Sua Sede localizase nas coordenadas geográficas de $22^{\circ} 44^{\prime} 40^{\prime \prime}$ de Latitude Sul e $42^{\circ} 51^{\prime} 34^{\prime \prime}$ de Longitude Oeste, a uma altitude de 46 metros e distante $40 \mathrm{~km}$ da capital do Estado (Figura 1). Possui clima tropical quente e úmido, chuvoso no verão e seco no inverno e temperatura média anual em torno de 23 (Itaboraí, 2018). De acordo com o Censo, em 2010, Itaboraí tinha uma população de 218.090 habitantes, com densidade demográfica era de 507 habitantes por $\mathrm{km}^{2}$. A taxa de urbanização em Itaboraí saltou de 94,5\% em 2000 para 98,8\% em 2010 (Itaboraí, 2018). 
Análise espacial dos determinantes socioambientais para leptospirose no município de Itaboraí-RJ, através da abordagem ecossistêmica
Jefferson Pereira Caldas Hermano Albuquerque Heitor Levy Ferreira Praça

Alexandre San Pedro Siqueira Luciano Medeiro de Toledo

Paulo Chagastelles Sabroza

Figura 1: Mapa do município de Itaboraí

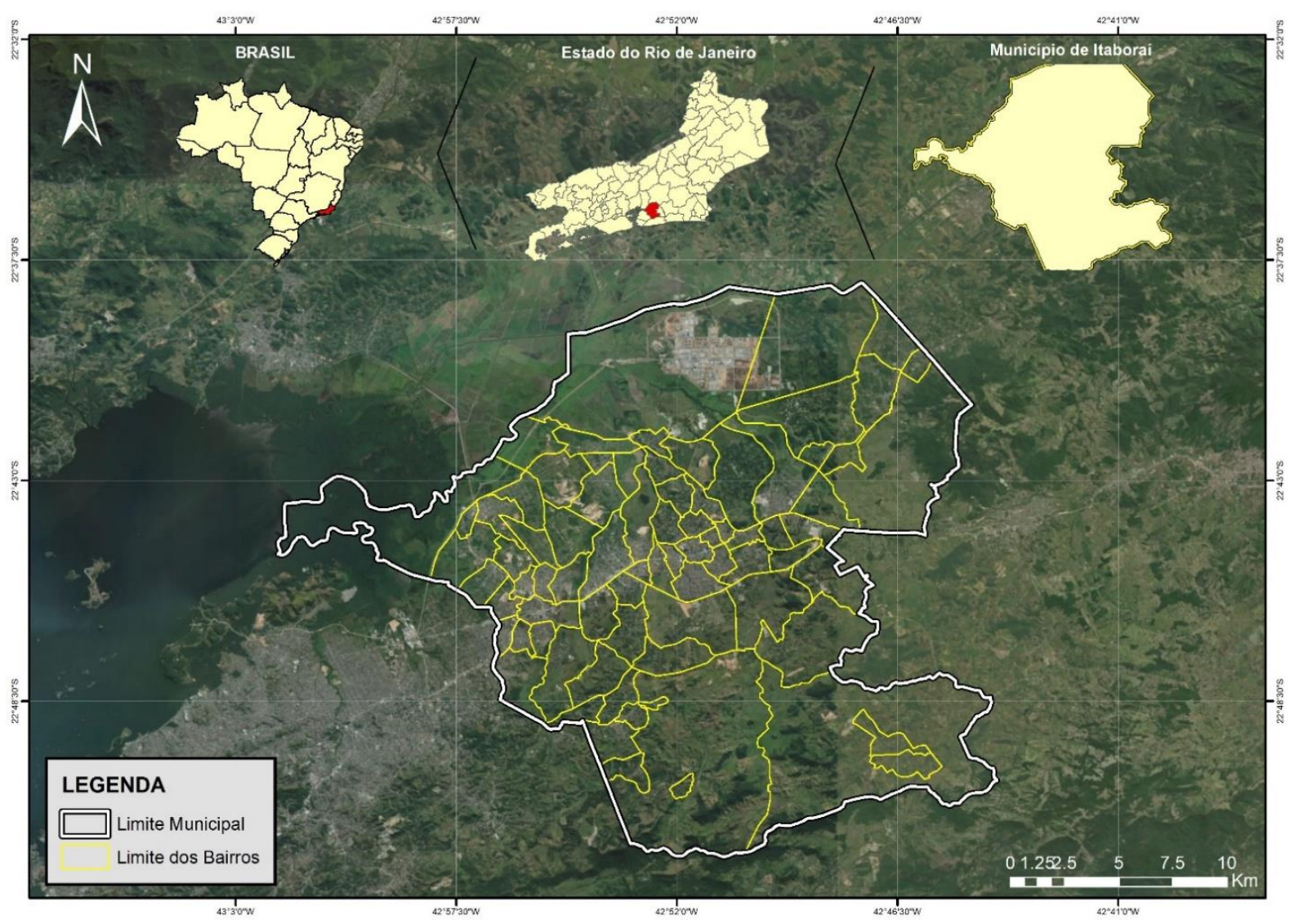

Elaborado pelos autores. Fonte dos dados: IBGE

\section{Dados Epidemiológicos}

Os dados referentes aos casos notificados de Leptospirose em Itaboraí no período de 2007 à 2018 foram obtidos junto a Secretaria Municipal de Saúde do município através de convênio de cooperação assinado por conta do plano de monitoramento epidemiológico realizado no município. O banco de dados foi trabalhado através da limpeza das duplicidades e correções de inconsistências. Foram selecionados para o estudo apenas os casos residentes no município. Os dados foram tabulados por ano e mapeados para possibilitar a análise temporal e espacial da incidência do agravo. Os casos foram georreferenciados a nível pontual através de ferramentas de geocodificação e também por busca ativa de endereços sem, no entanto, permitir a identificação geográfica do sujeito. Pela utilização de dados secundários onde os sujeitos não foram identificados o estudo não precisou entrar no processo de julgamento pelo comitê de ética.

\section{Áreas de maior risco de inundação}

Para a delimitação das áreas de maior risco de inundação através de modelagem multicriterial foram utilizados os seguintes planos de informação: hipsometria, declividade, geomorfologia, pedologia, hidrografia e uso do solo (Quadro 1). A escolha dos planos de informação da modelagem foi realizada através da revisão da literatura sobre o tema e avaliação dos determinantes do evento em questão. A metodologia consistiu na seleção das classes mais críticas, em cada plano de informação, para o evento de inundação. No plano da hipsometria foram selecionadas altitudes de até 20 metros acima do nível de base do município (nível do mar); no plano da declividade foram selecionadas as áreas 
Análise espacial dos determinantes socioambientais para leptospirose no município de Itaboraí-RJ, através da abordagem ecossistêmica
Jefferson Pereira Caldas Hermano Albuquerque Heitor Levy Ferreira Praça Alexandre San Pedro Siqueira Luciano Medeiro de Toledo

Paulo Chagastelles Sabroza

com até 10 graus de inclinação vertical; no plano da geomorfologia foram selecionadas as feições geomorfológicas de tabuleiros e planícies, que apresentam menor capacidade de escoamento superficial em função da suas declividades; no plano da pedologia as classes foram agrupadas em função da permeabilidade de cada tipo de solo sendo selecionados aqueles classificados como pouco permeáveis; no plano da hidrografia foram confeccionados e selecionados buffers de 50 metros para rios de $2^{\circ}$ e $3^{\circ}$ ordem e de 100 metros para rios de $4^{\circ}$ e $5^{\circ}$ ordem e para o plano de uso e ocupação do solo foram selecionadas as classes de áreas urbanas e rurais por serem fortemente antrópicas (Figura 2) (Hora \& Gomes, 2009; Menezes, 2014; Fernandes et al., 2014; Miranda, 2016; Monteiro \& Kobiyama, 2013). Após a seleção os planos de informação foram cruzados através da interseção dos mesmos, obtendo as áreas de maior risco de inundação. A seguir foi calculada uma área de influência de inundação através da confecção de um buffer de 100 metros em relação as áreas de maior risco de inundação visando abarcar a mobilidade dos roedores (Funasa, 2002).

Quadro1: Planos de informações utilizados no estudo

\begin{tabular}{|l|l|l|}
\hline \multicolumn{1}{|c|}{ Bases de Dados } & \multicolumn{1}{c|}{ Escala/Resolução } & \multicolumn{1}{c|}{ Fonte } \\
\hline Curvas de Nível & $1: 50000$ & Instituto Estadual do Ambiente - RJ \\
\hline Geomorfologia & $1: 50000$ & Instituto Estadual do Ambiente - RJ \\
\hline Pedologia & $1: 50000$ & Instituto Estadual do Ambiente - RJ \\
\hline Hidrografia & $1: 50000$ & Instituto Estadual do Ambiente - RJ \\
\hline Uso do Solo & $1: 10000$ & Confecção Própria \\
\hline Declividade & $1: 50000$ & Confecção Própria \\
\hline
\end{tabular}

Figura 2: Espacialização dos planos de informação utilizados no estudo

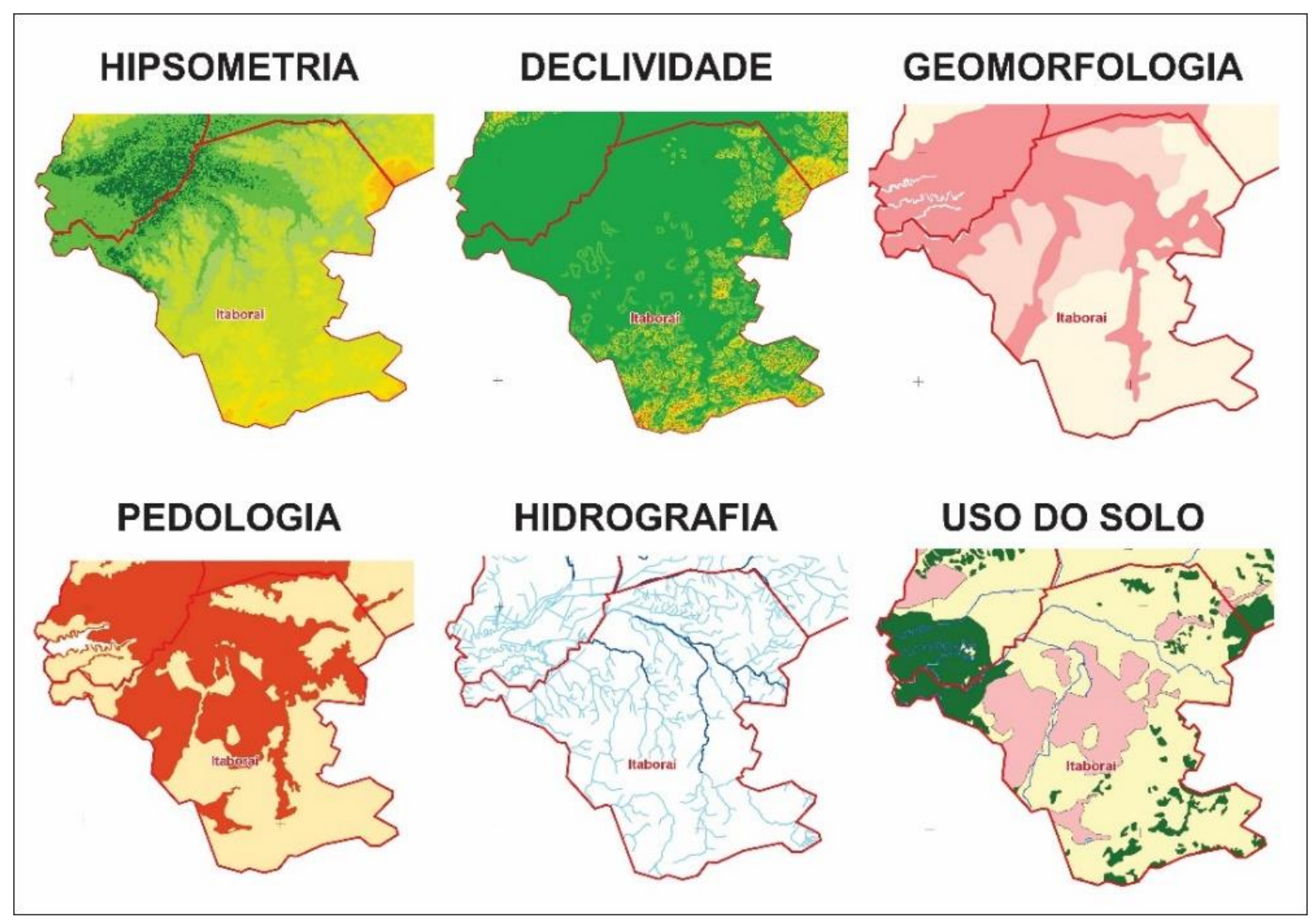


Análise espacial dos determinantes socioambientais para leptospirose no município de Itaboraí-RJ, através da abordagem ecossistêmica
Jefferson Pereira Caldas

Hermano Albuquerque Heitor Levy Ferreira Praça

Alexandre San Pedro Siqueira

Luciano Medeiro de Toledo

Paulo Chagastelles Sabroza

\section{Áreas Críticas em termos sociossanitários}

A identificação e demarcação das áreas críticas foi realizada por meio do contato direto com a realidade local, através do levantamento de informações em trabalhos de campo, pelo processamento das informações no laboratório, e validação dos resultados juntos aos profissionais de saúde e assistência social do município de Itaboraí, entre os anos de 2010 e 2012. Em função do desconhecimento da realidade local do município ao início do levantamento, a primeira etapa da metodologia para identificação e mapeamento das áreas foi o estabelecimento de contatos com técnicos das Secretarias Municipais os quais fossem capazes de indicar localidades com condições de vida e saúde precárias a serem visitadas. As informações dos técnicos foram complementadas por uma revisão de documentos (planos de desenvolvimento urbano, lei orgânica municipal e estudos sobre as condições urbanísticas do município). Os trabalhos de campo realizaram-se sempre em companhia de técnicos do nível local e consistiram na visitação das áreas, no registro fotográfico e georreferenciamento das mesmas por meio do uso de aparelhos de GPS. Foi realizada, nestas ocasiões, uma breve arguição sobre o fornecimento de água, serviço de esgoto, coleta de lixo, serviços de transporte e segurança local, a alguns moradores das localidades visitadas. Posteriormente foi feita a demarcação das áreas visitadas com o auxílio de imagens de satélite. Feita a demarcação, estas áreas foram mapeadas por meio do uso de ferramentas de geoprocessamento. Finalmente, este mapeamento foi levado aos técnicos do nível local para validação. Uma vez demarcadas as áreas, foi feita nova rodada de trabalhos de campo para realização da estimativa populacional das mesmas. Foi feita a contagem do número de residências em cada uma das áreas demarcadas e o número obtido foi multiplicado pela média da densidade domiciliar do setor censitário (IBGE, 2010) em que ela está inserida. Após a delimitação das áreas críticas foi calculada sua a área de influência através da confecção de um buffer de 100 metros em relação as áreas de maior risco de inundação visando abarcar a mobilidade dos roedores (Funasa, 2002).

\section{Análise espacial}

Foi realizada por meio de sobreposição dos temas de interesse (áreas de maior risco de inundação, áreas críticas e casos notificados de leptospirose) através da análise visual. Também foram realizadas análises espaciais de proximidade e de interseção espacial entre os referidos temas objetivando identificar o percentual de casos notificados localizados dentro ou próximo das áreas de influência de maior risco de inundação e das áreas críticas.

\section{Processamento e mapeamento dos dados}

Todos os procedimentos de geoprocessamento, análise espacial e mapeamento foram realizados dentro com programa de código aberto QGis Desktop 3.4.3. Tratamento e operação de banco de dados foram realizados no programa estatístico $\mathrm{R}$ (version3.4.4, https://www.r-project.org/) na plataforma RStudio.

\section{RESULTADOS}

Foram notificados de 2007 a 2018 no município de Itaboraí 89 casos residentes de Leptospirose, sendo os anos 2010 e 2007 os mais relevantes com 30 e 12 casos respectivamente (Quadro 2). A taxa de incidência média para o período foi de 7,42 casos por 100.000 habitantes.

As áreas de maior risco de inundação ficaram mais concentradas na porção Norte e Noroeste do município seguindo 0 curso do principal corpo hídrico do município, o Rio Caceribu. As áreas de risco localizadas na região central do município estão as margens dos rios constituintes da bacia hidrográfica do Caceribu, estas áreas de inundação se encontram nas áreas mais urbanizadas da cidade. A área total de risco de inundação totalizou $123 \mathrm{Km}^{2}$ representado assim $28 \%$ da área total do município (Figura 3). 
Análise espacial dos determinantes socioambientais para leptospirose no município de Itaboraí-RJ, através da abordagem ecossistêmica
Jefferson Pereira Caldas Hermano Albuquerque Heitor Levy Ferreira Praça Alexandre San Pedro Siqueira Luciano Medeiro de Toledo

Paulo Chagastelles Sabroza

Quadro 2: Número de casos notificados e incidência de casos de leptospirose no município de Itaboraí - RJ, nos anos de 2007 a 2018.

\begin{tabular}{c|c|c|c|c|c|c|c|c|c|c|c|c|}
\hline & & 200 & 200 & & 201 & 201 & 201 & 201 & 201 & 201 & 201 & 201 \\
Anos & 2007 & 8 & 9 & 2010 & 1 & 2 & 3 & 4 & 5 & 6 & 7 & 8 \\
\hline $\begin{array}{c}\text { Casos } \\
\text { Incidência (por 100.000 } \\
\text { hab) }\end{array}$ & 12 & 7 & 4 & 30 & 6 & 5 & 8 & 5 & 3 & 2 & 3 & 4 \\
\cline { 2 - 23 } & 5.50 & 3.21 & 1.83 & 6 & 2.75 & 2.29 & 3.67 & 2.29 & 1.38 & 0.92 & 1.38 & 1.83 \\
\hline
\end{tabular}

Fonte: SINAN

Figura 3: Mapa das áreas de maior risco de inundação em Itaboraí

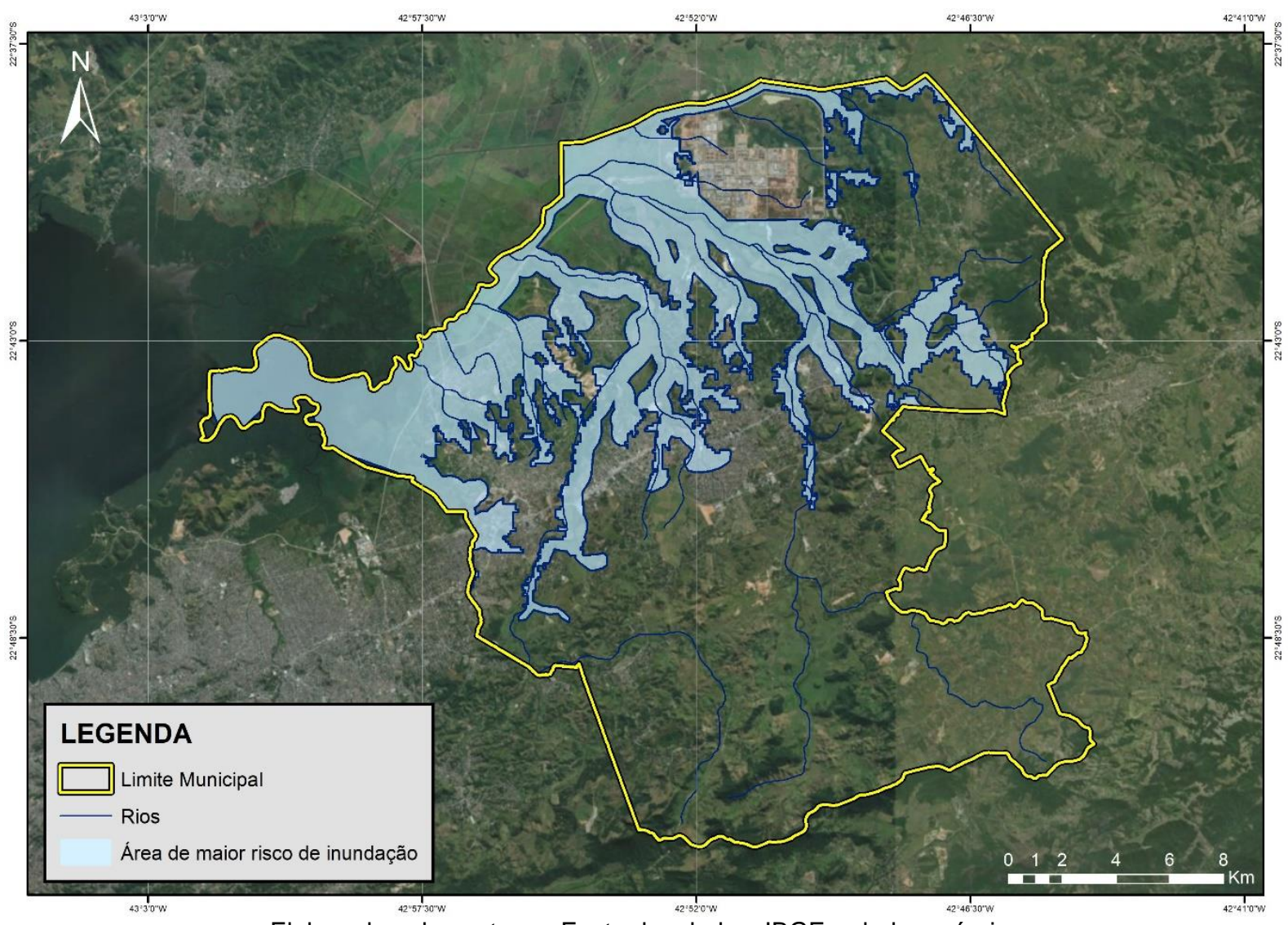

Elaborado pelos autores. Fonte dos dados: IBGE e dados próprios

Foram identificadas 27 áreas críticas no município de Itaboraí localizadas em sua grande maioria na periferia urbana imediata e ou as margens dos corpos hídricos (Figura 4). Apresentam grande variação tanto em área, (a menor com aproximadamente $13.409 \mathrm{~m}^{2}$ de área e a maior com 559.605 $\mathrm{m}^{2}$ ) quanto em população (a mais populosa com 2.642 habitantes e a menos populosa 139) (Tabela 1). Somadas as suas áreas equivalem a $0.8 \%$ do território municipal e suas populações somadas representam $9.3 \%$ da população total residente no município.

Dos 89 casos notificados de leptospirose 64 foram localizados dentro das áreas de influência de inundação o que corresponde a $71 \%$ dos casos e 31 dentro das áreas críticas o que corresponde a $34 \%$ do total. Vale ressaltar que apenas $9.3 \%$ da população total do município reside em áreas críticas, o que torna a concentração de casos aí observada ainda mais dramática. Além disso, análise 
Análise espacial dos determinantes socioambientais para leptospirose no município de Itaboraí-RJ, através da abordagem ecossistêmica
Jefferson Pereira Caldas Hermano Albuquerque Heitor Levy Ferreira Praça Alexandre San Pedro Siqueira Luciano Medeiro de Toledo

Paulo Chagastelles Sabroza

espacial mostrou que, das 27 áreas críticas, 26 se encontram dentro das áreas de maior risco de inundação correspondendo a cerca de $99 \%$ do total (Figura 5).

Tabela 1: Características gerais das áreas críticas

\begin{tabular}{|c|c|c|c|c|c|}
\hline CÓDIGO & NOME & $\begin{array}{l}\text { ÁREA } \\
\left(\mathrm{m}^{2}\right)\end{array}$ & $\begin{array}{l}\text { DOMICÍL } \\
\text { IOS }\end{array}$ & $\begin{array}{l}\text { HABITAN } \\
\text { TES }\end{array}$ & $\begin{array}{c}\text { DENSIDA } \\
\text { DE } \\
\text { (hab/Km² } \\
\text { ) }\end{array}$ \\
\hline ECITA01 & ASSENTAMENTO JARDIM ITAMBI & $\begin{array}{r}400780.4 \\
3\end{array}$ & 482 & 1677.36 & 4185.23 \\
\hline ECITA02 & $\begin{array}{l}\text { ASSENTAMENTO POPULAR A } \\
\text { MARGEM DO TINGIDOR }\end{array}$ & 49520.57 & 128 & 416 & 8400.55 \\
\hline ECITA03 & BAIRRO ESPERANÇA & $\begin{array}{r}485120.0 \\
3\end{array}$ & 796 & 2642.72 & 5447.56 \\
\hline ECITA04 & BARREIRO 1 E 2 & $\begin{array}{r}559605.9 \\
9\end{array}$ & 481 & 1640.21 & 2931.01 \\
\hline $\begin{array}{l}\text { ECITA05 } \\
\text { ECITA06 }\end{array}$ & $\begin{array}{l}\text { CANAL TABICU 2-BACIA } \\
\text { CANAL TAMBICU 1-VILA DO CAMPO }\end{array}$ & $\begin{array}{l}13409.05 \\
54842.00\end{array}$ & $\begin{array}{r}43 \\
174\end{array}$ & $\begin{array}{l}157.38 \\
535.92\end{array}$ & $\begin{array}{r}11736.86 \\
9772.07\end{array}$ \\
\hline ECITA07 & $\begin{array}{l}\text { COLÔNIA TAVARES DE MACEDO } \\
\text { ÁREA } 2\end{array}$ & 94768.28 & 85 & 253.3 & 2672.84 \\
\hline ECITA08 & $\begin{array}{l}\text { COLÔNIA TAVARES DE MACEDO- } \\
\text { HANSENÍASE }\end{array}$ & $\begin{array}{r}144888.6 \\
6\end{array}$ & 175 & 525 & 3623.47 \\
\hline ECITA09 & CORREGO FUNDO & 65448.93 & 235 & 737.9 & 11274.44 \\
\hline ECITA10 & ENGENHO VELHO & $\begin{array}{r}209401.2 \\
6\end{array}$ & 382 & 1340.82 & 6403.11 \\
\hline ECITA12 & ITAMBI-BAIRRO AMARAL & $\begin{array}{r}115553.3 \\
9\end{array}$ & 120 & 385.2 & 3333.52 \\
\hline ECITA13 & ITAMBI-JOÃO CAETANO & 14826.93 & 90 & 280.8 & 18938.52 \\
\hline ECITA14 & MARGEM DO GOIANÁ & $\begin{array}{r}155837.8 \\
7\end{array}$ & 699 & 2285.73 & 14667.36 \\
\hline ECITA15 & $\begin{array}{l}\text { NANCILÂNDIA-VENDAS DAS } \\
\text { PEDRAS }\end{array}$ & 25966.94 & 87 & 278.4 & 10721.33 \\
\hline ECITA16 & $\begin{array}{l}\text { OCUPAÇÃO A MARGEM DO RIO } \\
\text { ALDEIA }\end{array}$ & 47872.25 & 193 & 604.09 & 12618.79 \\
\hline ECITA17 & $\begin{array}{l}\text { OUTEIRO DAS PEDRAS-CAMPO DA } \\
\text { LIXEIRA }\end{array}$ & 13444.58 & 71 & 209.45 & 15578.78 \\
\hline $\begin{array}{l}\text { ECITA18 } \\
\text { ECITA19 }\end{array}$ & $\begin{array}{l}\text { OUTEIRO DAS PEDRAS 2-LAGOA } \\
\text { PENEDO } 2\end{array}$ & $\begin{array}{l}51842.34 \\
30021.07\end{array}$ & $\begin{array}{r}145 \\
60\end{array}$ & $\begin{array}{l}452.4 \\
180.6\end{array}$ & $\begin{array}{l}8726.46 \\
6015.78\end{array}$ \\
\hline ECITA20 & RATO MOLHADO I & $\begin{array}{r}132537.2 \\
2\end{array}$ & 230 & 731.4 & 5518.45 \\
\hline ECITA21 & RATO MOLHADO II & $\begin{array}{r}146473.3 \\
3\end{array}$ & 255 & 867 & 5919.16 \\
\hline ECITA21 & RETA DA LARANJA & $\begin{array}{r}221516.5 \\
4\end{array}$ & 405 & 1372.95 & 6197.96 \\
\hline ECITA22 & USINA & 33329.18 & 285 & 934.8 & 28047.50 \\
\hline ECITA23 & $\begin{array}{l}\text { VILA PORTUENSE-PORTO DAS } \\
\text { CAIXAS }\end{array}$ & 27703.13 & 117 & 369.72 & 13345.79 \\
\hline ECITA24 & VISCONDE DE ITABORAÍ & 62592.55 & 55 & 202.95 & 3332.42 \\
\hline ECITA25 & VILA BRASIL & 7 & 289 & 869.89 & 5930.92 \\
\hline $\begin{array}{l}\text { ECITA26 } \\
\text { ECITA27 }\end{array}$ & $\begin{array}{l}\text { MANILHA } \\
\text { JOAQUIM DE OLIVEIRA }\end{array}$ & $\begin{array}{l}63825.96 \\
23457.44\end{array}$ & $\begin{array}{l}74 \\
42 \\
\end{array}$ & $\begin{array}{l}224.22 \\
139.44\end{array}$ & $\begin{array}{l}3512.99 \\
5944.38\end{array}$ \\
\hline
\end{tabular}


Análise espacial dos determinantes socioambientais para leptospirose no município de Itaboraí-RJ, através da abordagem ecossistêmica
Jefferson Pereira Caldas Hermano Albuquerque Heitor Levy Ferreira Praça Alexandre San Pedro Siqueira Luciano Medeiro de Toledo Paulo Chagastelles Sabroza

Figura 4: Mapa das áreas críticas em Itaboraí

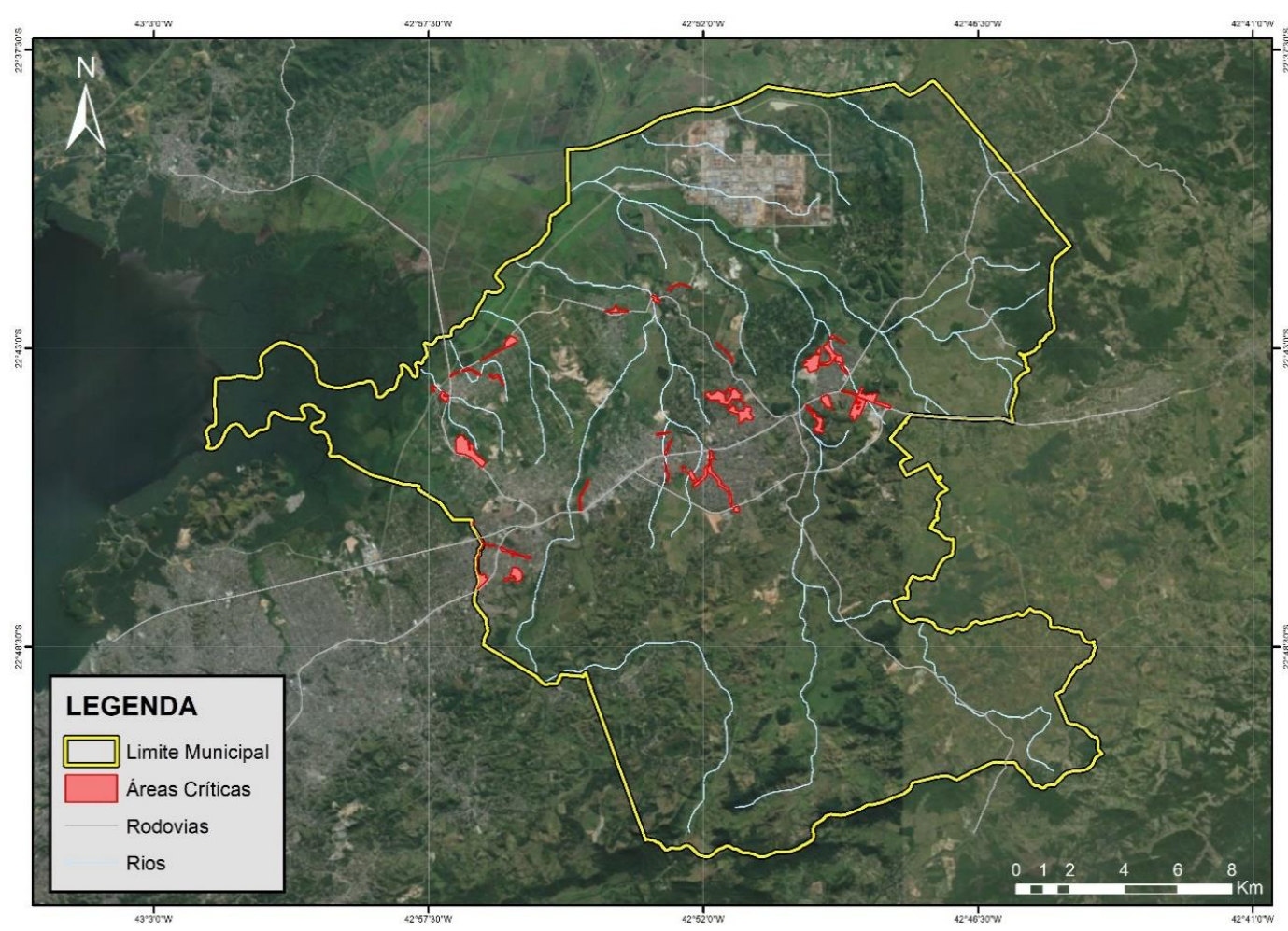

Elaborado pelos autores. Fonte dos dados: IBGE e dados próprios.

Figura 5: Mapa dos casos de Leptospirose, áreas de maior risco de inundação e áreas críticas

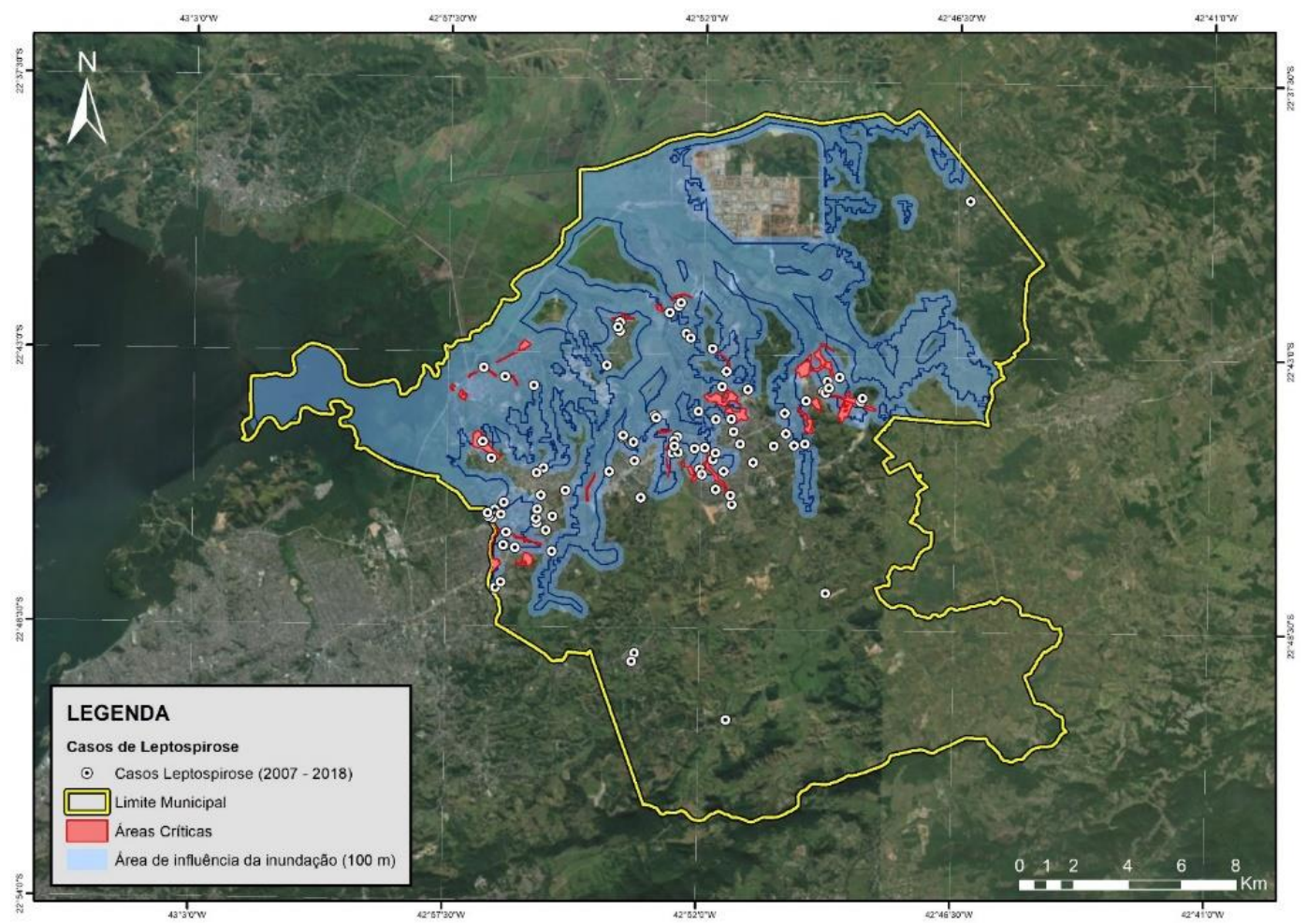

Elaborado pelos autores. Fonte dos dados: SINAN, IBGE e dados próprios 
Análise espacial dos determinantes socioambientais para leptospirose no município de Itaboraí-RJ, através da abordagem ecossistêmica
Jefferson Pereira Caldas Hermano Albuquerque Heitor Levy Ferreira Praça Alexandre San Pedro Siqueira Luciano Medeiro de Toledo

Paulo Chagastelles Sabroza

\section{DISCUSSÃO}

A delimitação das áreas de risco para leptospirose no município de Itaboraí através da utilização de informações referentes às áreas de influência de inundação, ocorrência de casos e das localidades com precariedade de condições sociossanitárias aponta para uma situação de vulnerabilidade socioambiental marcada pela sobreposição espacial de populações com precárias condições materiais de vida habitando ou circulando em áreas sujeitas a inundações. Adicionalmente, a ocorrência injusta, desproporcional e evitável de leptospirose naquelas localidades ressalta uma situação de iniquidade social em saúde na qual populações com menores condições econômicas são impelidas a ocupar porções do território ambientalmente degradadas e com menor disponibilidade de serviços públicos.

Os resultados encontrados no estudo destacam a importância do desenvolvimento de abordagem conceituais e metodológicas que busquem compreender a ocorrência dos problemas de saúde e sua relação com os múltiplos fatores determinantes visando o desenvolvimento de uma vigilância da leptospirose que considere as características socioambientais particularidades do território em que planeja e executa suas ações.

No âmbito dos serviços de saúde, a integração de informações referentes as caraterísticas socioambientais do território e análise da distribuição espacial da leptospirose vem se configurando como uma promissora abordagem não apenas para a área da vigilância, mas também como possibilidade de interlocução de propostas de intervenção que articulem o setor saúde com outros setores governamentais municipais voltados para habitação, saneamento e assistência social.

\section{REFERÊNCIAS}

ALEIXO, N. C. R; NETO, J. L. S. Rainfall events extremes and health: Perspectives of interaction by leptospirosis cases in urban environment. Hygeia -Revista Brasileira de Geografia Médica da Saúde. v. 6, n. 11, p. 118-132, 2010.

BRASIL, Fundação Nacional de Saúde. Manual de Controle de Roedores. 2002.

BRASIL, Ministério da Saúde - Secretaria de Vigilância em Saúde. Guia de Vigilância em Saúde. 2017.

BRASIL, Ministério das Cidades. Guia para regulamentação e implementação de Zonas Especiais de Interesse Social - ZEIS em Vazios Urbanos. 2009.

CERUTTI, D. F; TAMBELLINI, A. T. Análise dos Danos Humanos Decorrentes de Desastres

Associados a Chuvas, Ventos, Granizo e Escorregamentos, no Brasil, 2003-2007. Curso

Internacional sobre Saúde, Desastres e Desenvolvimento. Brasília, 2008.

CHANGE, IPCC Climate et al. The physical science basis. Contribution of Working Group I to the fourth assessment report of the Intergovernmental Panel on Climate Change, v. 996, 2007.

DA SILVA, Paulo Vitor Ribeiro Marques; JUNIOR, Ricardo Abranches Félix Cardoso; DE NORONHA, Gustavo Carneiro. Mapeamento e análise de risco de inundação da Bacia do Rio Paraíba/AL: estudo de caso. Sistemas \& Gestão, v. 11, n. 4, p. 431-443, 2017. https://doi.org/10.20985/1980$\underline{5160.2016 . v 11 n 4.1143}$

FERNANDES DA SILVA, P. C.; ANDRADE, E; ROSSINI-PENTEADO, D. Mapeamento de perigos e riscos de inundação: Uma abordagem semiquantitativa. Revista do Instituto Geológico, v. 35, n. 2, 2014. https://doi.org/10.5935/0100-929X.20140007

FREITAS, C. M; XIMENES, E. F. Enchentes e saúde pública: uma questão na literatura científica recente das causas, consequências e respostas para prevenção e mitigação. Ciência \& Saúde Coletiva, v. 17, n. 6, p. 1601-1616, 2012. https://doi.org/10.1590/S1413-81232012000600023

GONÇALVES, A. J. R.; CARVALHO, J. E. M.; SILVA, J. B. G. et al. Hemoptise/s e síndrome de angústia respiratória do adulto como causas de morte na leptospirose: mudanças de padrões clínicos e anatomopatológicos. Revista da Sociedade Brasileira de Medicina Tropical, v. 25, n. 4, p. 261270, 1992. https://doi.org/10.1590/S0037-86821992000400009 
Análise espacial dos determinantes socioambientais para leptospirose no município de Itaboraí-RJ, através da abordagem ecossistêmica
Jefferson Pereira Caldas Hermano Albuquerque Heitor Levy Ferreira Praça Alexandre San Pedro Siqueira Luciano Medeiro de Toledo Paulo Chagastelles Sabroza

HORA, S. B.; GOMES, R. L. Mapeamento e avaliação do risco a inundação do Rio Cachoeira em trecho da área urbana do Município de Itabuna/BA. Sociedade \& Natureza, v. 21, n. 2, p. 57-75, 2009. https://doi.org/10.1590/S1982-45132009000200005

IBGE, Instituto Brasileiro de Geografia e Estatística. Censo Demográfico 2010: Resultados do Universo por setor censitário. 2011. Disponível em: <https://censo2010.ibge.gov.br/>.

INEA, Instituto Estadual do Ambiente. Elaboração do Plano Estadual de Recursos Hídricos do Estado do Rio de Janeiro. 2014.

ITABORAÍ, Vigilância Ambiental em Saúde - VAS. Plano de contigência de enfrentamento de desastres naturais do município de Itaboraí - RJ. 2018.

MILLENNIUM ECOSYSTEM ASSESSMENT, M. E. A. Ecosystems and human well-being. Synthesis, 2005.

MENEZES, D. J. Zoneamento das áreas de risco de inundação na área urbana de Santa Cruz do Sul - RS. p. 137, 2014.

MENEZES FILHO, F. C. M.; AMARAL, D. B. Histórico da expansão urbana e ocorrência de inundações na cidade de Cuiabá-MT. Sociedade \& Natureza, v. 26, n. 1, p. 159-170, 2014. https://doi.org/10.1590/1982-451320140111

MIRANDA, F. M. Índice de susceptibilidade do meio físico a inundações como ferramenta para o planejamento urbano [dissertação]. Rio de Janeiro: Universidade Federal do Rio de Janeiro, 2016.

MONTEIRO, L.; KOBIYAMA, M. Proposta de metodologia de mapeamento de perigo de inundação. Revista de Gestão de Água da América Latina, v. 10, n. 2, p. 13-25, 2013. https://doi.org/10.21168/rega.v10n2.p13-25

OPEN SOURCE GEOSPATIAL FOUNDATION PROJECT. QGIS Geographic Information System. [s.I.]: QGIS Development Team, 2019. Disponível em: <http://qgis.osgeo.org>.

TEAM, R. Core et al. R: A language and environment for statistical computing. Vienna, Austria: $\mathbf{R}$ Foundation for Statistical Computing, [s.d.]. 2019. Disponível em: <URL https://www.R-project.org/.>.

ROSEN, Carol; TUNSTALL, Dan; WHITE, Robin; et al. World Resources 2000 - 2001. 2000.

TEIXEIRA, Carmem Fontes; PAIM, Jairnilson Silva; VILASBÔAS, Ana Luiza. SUS, modelos assistenciais e vigilância da saúde. Informe Epidemiológico do Sus, v. 7, n. 2, p. 7-28, 1998. https://doi.org/10.5123/S0104-16731998000200002 